\title{
An unexpected low Hepatitis B seroprevalence in pregnant women from the rural Southeastern Turkey
}

\author{
Ali Yavuzcan ${ }^{1 \star}$, Akif Altınbas ${ }^{2}$ and Sibel Altınbas ${ }^{3}$ \\ ${ }^{1}$ Department of Obstetric and Gynecology, Hakkari State Hospital, Hakkari, Turkey. \\ ${ }^{2}$ Department of Internal Medicine, Hakkari State Hospital, Hakkari, Turkey. \\ ${ }^{3}$ Department of Obstetric and Gynecology, Dr. Zekai Tahir Burak Women Health Teaching and Research Hospital, \\ Ankara, Turkey.
}

Accepted 16 September, 2011

\begin{abstract}
The purpose of this study was to investigate the sero-prevalence of Hepatitıs B virus (HBV) infection among pregnant women in city of Hakkari that lies in the Southeastern border of Turkey in which the socioeconomic status of people is too low. Hepatitis B seroprevalence antigen (HBs Ag) positivity, anti HBs positivity and demographic datas of the women (ages, born places etc.) were determined from the records of Hakkari State Hospital. HBs Ag positivity was detected in 7 of 473 (1.47\%) pregnant women. There were no significant difference between the age groups and prevalence of HBs $\mathrm{Ag}$ positivity $(\mathrm{p}=$ 0.994 and $p<0.05$ ). Antibodies against HBs Ag (anti HBs) were performed in 443 pregnant women. Only 59 of them $(11,4 \%)$ were positive. The prevalence of HBs Ag positivity in Hakkari was found lower than expected. The Southeastern part of Turkey should not been accepted as an intermediate endemic area for HBV. On the other hand; according to us, the active screening of pregnant women in a proper population is one of the most important strategies for defeating the addition of new infectious members.
\end{abstract}

Key words: Hakkari, Hepatitis B antigen positivity, pregnant women.

\section{INTRODUCTION}

Hepatitis B virus (HBV) is a worldwide problem that affected about 350 million people. HBV infection may lead to acute, fulminant or chronic hepatitis, liver cirrhosis and liver carcinoma (Ganem and Prince, 2004). In endemic areas, most individuals are infected by vertical transmission. The exposure of HBV happened during the delivery, in uterus or in the early childhood (Proceedings of the European Association for the Study of the Liver, 2002). Passive immunoprophylaxis with hepatitis $B$ immunoglobulin (HBIG) and active immunoprophylaxis with hepatitis B vaccine in the infants of HBV carriers; gives high levels of protection against vertical transmission. However, $10 \%$ of the offspring of HBV carriers are chronic hepatitis B sufferers in their early life. Even though these carriers received routine neonatal immunoprophylaxis, it is because they were infected in uterus (Lee et al., 2006). As a result of this, maternal

*Corresponding author. E-mail: draliyavuzcan@yahoo.com. Tel: 0090438 2117755, 00905053185878 . Fax: 00904382117470. screening is necessary for the treatment of newborns, since passive and active immunization are so important in the endemic areas.

The recent studies revealed that HBV prevalence in Turkey was between 4 to $5 \%$, increased from west to east region (2 to $4 \%$ to 3.9 to $12.5 \%$ ). It was published that the seroprevalence of hepatitis B had decreased markedly between 1989 and 2004 in Turkey from 4.19 to $2.10 \%$ (Gurol et al., 2006). In the intermediate HBV prevalence areas like Turkey, the transmission of HBV frequently occurred by horizontally (Degertekin et al., 2000). Major transmission modes of are HBV vertical (perinatal), horizontal, sexual and parenteral. Also perinatal, household, sexual transmission represented as a major mode of horizontal transmission modes. However, we got a few data about HBs Ag positivity in the city of Hakkari, which lies between Irak in the south and Iran in the east border. Hakkari is also one of the poorest cities of Turkey in terms of socioeconomic status of citizens. In Zahedan, Iran, $6.5 \%$ of pregnant women are HBsAg positive (Mood et al., 2004). Unfortunately, Iraq was rated among the groups of countries with high 
Table 1. Percentages of HBs Ag carrier in pregnant women in different age groups.

\begin{tabular}{ccccc}
\hline Ages & N (\%) & $\begin{array}{c}\text { HBs Ag positivity } \\
\text { Individuals (\%) }\end{array}$ & $\begin{array}{c}\text { HBs Ag negativity } \\
\text { Individuals (\%) }\end{array}$ & p value \\
\hline Below 25 & $151(31)$ & $3(1,98)$ & $148(98,02)$ & 0.994 \\
$26-30$ & $165(34)$ & $2(1,2)$ & $163(98,80)$ & \\
$31-35$ & $86(18)$ & $1(1,6)$ & $85(98,40)$ & \\
Over 36 & $71(15)$ & $1(1,4)$ & $70(98,60)$ & \\
Total & 473 & $7(1,47)$ & $466(98,53)$ & \\
\hline
\end{tabular}

${ }^{*} p<0.05$ was considered significant.

endemicity of hepatitis B in recent years (UNICEF, 2003). In the English literature, there was a report which revealed that $\mathrm{HBs} \mathrm{Ag}$ positivity in Van, the nearest city to Hakkari, was 2.92\% (Degertekin et al., 2000).

This study was conducted to investigate the prevalence of HBV infection among pregnant women in city of Hakkari that lie in the southeastern border of Turkey in which the socioeconomic status of people is too low.

\section{MATERIALS AND METHODS}

The data of all pregnant women who were born in the same city admitted to Hakkari State Hospital between January and March 2009 were investigated, retrospectively. Totally, 473 of pregnant women were included into the study. A sensitive and automated chemiluminescent micro particle immunoassay for quantitative determination of hepatitis B virus surface antigen and anti hepatitis $B$ antibody in human sera was used. The Siemens ad via centaur $\mathrm{cpR}$ device was utilized.All virological tests were performed in the Hakkari State Hospital Laboratories, Turkey.

Statistical Package for Social Sciences 11.5 for Windows 98 was used for the statistical analyses (SPSS Inc., Chicago, IL, USA). The relations between the data were analyzed by the chi-square test. $P$ value less than 0.05 was considered statistically significant.

\section{RESULTS}

During the study period, 473 pregnant women with a mean age of 28 (range, 14 to 53) were admitted to Hakkari State Hospital. HBs Ag was detected in 7 out of 473 (1, 47\%) pregnant women (Table 1). The percentages of HBs Ag positivity were similar between the different age groups (Table 1) $(p=0.994$ and $p<$ 0.05). Alanin amino transpherase (ALT) and aspartate amino transferase. (AST) values of $\mathrm{HBs}$ ag positive pregnant women were in normal limits (ranges, 11 to $29 \mathrm{IU} / \mathrm{lt}$ and 14 to $39 \mathrm{IU} / \mathrm{lt}$ ). Antibodies against HBs ag (anti HBs) were performed in 443 pregnant women in which only 59 out of them (11.4\%) were positive .

\section{DISCUSSION}

Hepatitis B virus (HBV) can be transmitted either perinatally or horizontally to the child. Perinatal transmission from highly infectious mothers to their neonates is an important route for HBV infection in Asian countries and endemic areas (Stevens et al., 1975). Mother-to-infant transmission of HBV includes intrauterine transmission, intrapartum transmission, and postpartum transmission. Neonatal administration of HBIG combined with hepatitis B vaccine has proved highly effective in preventing intrapartum and postpartum transmission of HBV (Lee et al., 2006). Identification and treatment of infants born to $\mathrm{HBsAg}$-positive women is important, because without prophylaxis, $48 \%$ of infants born to HBsAg-positive women become infected (Mahoney, 1999 ). An estimated 24\% of the 1.25 million people with chronic HBV infection in the United States were infected during the perinatal period (Margolis et al., 1995). With appropriate timely immunoprophylaxis, > $90 \%$ of these perinatal infections can be prevented (Shapiro and Margolis, 1992). It is recommended in Turkey to immunize all infants born by an HBV carrier with hepatitis B vaccine and HBIG. As for intrauterine transmission, it has been suggested that administering HBIG to pregnant women neutralizes HBV in the maternal body, thereby reducing HBV viremia and the risk of intrauterine infection but the efficiency and safety of this treatment is considered controversial (Zhu et al., 2003).

This is the first published study; documenting seroprevalence of HBV among pregnant women from Hakkari. Hakkari is located in the Southeastern region of Turkey just near of the border to Iran and Iraq (Figure 1). The city of Hakkari got no immagration from the other cities of Turkey. Border trade and livestock are livelihoods. Border trade could not be done due to the Iraq War. The livestock does not have good income. So there is a very high level of unemployment. The expected HBV prevalence of individuals living in Hakkari had been high. Low socioeconomic status and poor hygiene could be an important factors for horizontal transmission in this group. Despite the report that denoted the overall prevalence of HBV was decreased from $4.92 \%$ in 1989 to $2.10 \%$ in 2004 in Turkey (Gurol et al., 2006). The last observation from this part of country performed in four cities (Diyarbakır, Mardin, Sanliurfa and Batman), designed as a cluster sampling method, revealed the 


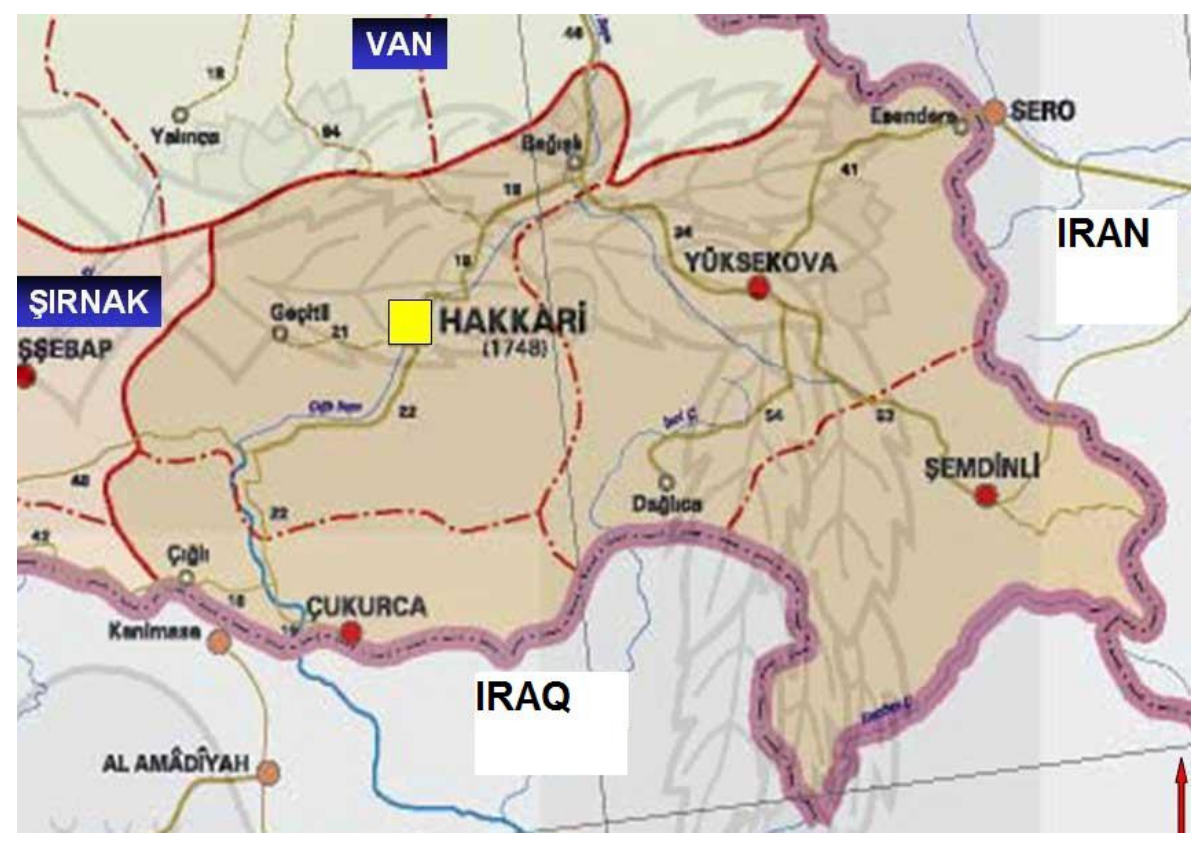

Figure 1. Location of Hakkari. ( from website of http://hakkari.meb.gov.tr).

seroprevalence of $\mathrm{HBs}$ ag positivity as $8.2 \%$ in the rural, and $6.2 \%$ in the urban areas (Dursun et al., 2005). Another study from Degertekin et al. (2000) reported the prevalence of HBV was $10 \%$ in adults in Diyarbakır (Degertekin et al., 2000). The number of the reports about the prevalence of HBV in Hakkari is limited in English literature. One study was carried out in a wide area including Hakkari. Hbs Ag positivity was found as 43/432 (5.04\%) between young girls ( Üner et al., 2001) . It was reported in another study, including Hakkari, that HBsAg positivity was found as $2.55 \%$ in blood donors at Eastern Turkey (Dilek et al., 2007). Our results were lower than those reported in the literature $(2.55$ and $5.04 \%)$. From the highlights of recent studies, much lower prevalence of HBV is seen than expected for the Southeastern regions of Turkey. It should also take into account that some recent analysis showed that the prevalence of HBV among men were high than that of women (9.8\% for men, and $6.8 \%$ for women) in Turkey (Dursun et al., 2005). The overall prevalence of HBsAg $(+)$ in pregnant women was $2.89 \%$ in Greece which is one of the neighboring countries of Turkey (Papaevangelou et al., 2006). Also the levels of HBsAg carrier stated among pregnant women were different in Moscow and Uzbekistan (1.1 and 6.9\%, respectively) (Kuzin et al., 1990). Iraq has intermediate endemicity at the year 2000 but raised in the group of countries of high endemicity of hepatitis B in recent years (André, 2000; UNICEF, 2003); although the prevelance rates depend on the different regions of Iran. Tajbakhsh et al. (2010) $f$ ound that the number of $\mathrm{HbsAg}$ positive patients was 90. However, in their study, Iran was seen as a low prevelance area for Hepatitis B, but in this study, different from the neighbourhood countries; prevalence of $\mathrm{HBsAg}$ positivity in pregnant women was found as $1.47 \%$ in Hakkari .

The percentages of HBs Ag carriers between the age groups did not differ significantly in our study (Table 1). In contrast, the percentages were reduced with the growing ages in a study performed with German women (Knorr, 2008). Also it is shown in previous studies that younger maternal age was an identifiable risk factor for $\mathrm{HBsAg}$ positivity (Papaevangelou et al., 1998, 2006).

The frequency of anti-HBs was used to evaluate both the vaccination coverage and recovery from HBV infection, but we could not determine the prevalence of isolated anti $\mathrm{HBC}$ positivity because of technical difficulties. The prevalence of anti HBs positivity were 2 to $4 \%$ in low endemic areas, 20 to $55 \%$ in intermediate, and 70 to $95 \%$ in high endemic areas (Proceedings of the European Association for the Study of the Liver, 2002). Our results for anti HBs positivity (11.4\%) did not seem to fit for the data of intermediate endemic areas.

All countries have agreed to be included the hepatitis B vaccine in routine immunization schedule since 1997 according to recommendation of World Health Organization. A routine vaccination programme against Hepatitis-B disease has commenced since 1998, due to the order of the Turkish Ministry of Health. All of the people at high risk for developing the disease were included in this immunization programme. Hepatitis B vaccination was completed among the children with primary education in the 2007 to 2008 year in Hakkari (Bulletin of the Turkish Ministry of Health, 2009). 
According to data from the Turkish Ministry of Health in 2004, routine hepatitis B vaccination rate in our country was $77 \%$ (Bulletin of the Turkish Ministry of Health, 2004). As a result of routine immunization in many countries; the prevalence of HBV infection has been decreased dramatically among adolescents (Lavanchy, 2004). The active immunization against HBV infection was succesfully obtained in Hakkari. On the other hand; Hakkari is a city which does not take any migration from surrounding cities. These two factors can explain the low prevalence of HBV infection and also the lower rate of infectivity in this area for decades among pregnant women. Of course from the data obtained from a borderline city in Turkey regarding the prevalence of HBV in pregnant women can not generalize it to the whole country. The frequency of serological HBV markers is widely variable among different cities of Turkey. But the most important point is that the southeastern part of Turkey should not been accepted an intermediate endemic area for HBV. When crosssectional studies with more patient in Southeastern Turkey, Iran and Iraq is conducted, we can say that all of this area is not anymore an intermediate area for Hepatitis B.

Also vertical transmission is the most important mode of infection in children below five years. It is inferred that HBV immunization should begin at birth (Chakravarti et al., 2005). According to this study, the active screening of pregnant women in a proper population is one of the most important strategies for defeating the addition of new infectious members.

In conclusion, giving information about hepatitis $B$ virus and transmission modes to the public; detecting all pregnant women and providing immunisation successfully at birth are the key points of defeating hepatit B virus.

\section{REFERENCES}

André $F$ (2000). Hepatitis B epidemiology in Asia, the Middle East and Africa. Vaccine, 8: 20-22.

Bulletin of the Turkish Ministry of Health (2004).

Bulletin of the Turkish Ministry of Health (2009).

Chakravarti A, Rawat D, Jain M (2005). A study on the perinatal transmission of the hepatitis B virus. Indian J. Med. Microbiol., 23: 128-130.

Degertekin H, Tuzcu A, Yalçin K (2000). Horizontal transmission of HBV infection among students in Turkey. Pub. Health, 114: 411-412.
Dilek I,Demir C, Bay A, Akdeniz H, Öner FA (2007).Seropositivity rates of HBsAg, anti-HCV, anti-HIV and VDRL in blood donors at Eastern Turkey. Turk. J. Hematol., 4: 4-7.

Dursun M, Meliksah E, Serif Y, Gunay S, Ozekinci T, Simsek Z (2005). Prevalence of Hepatitis $B$ infection in the Southeastern region of Turkey: Comparision of risk factors for HBV infection in rural and urban areas. Jpn. J. Infect. Dis., 58: 15-19.

Ganem D, Prince AM (2004). Hepatitis B virus infection natural history and clinical consequences. N Engl. J. Med., 350: 1118-1129.

Gurol E, Saban C, Oral O, Cigdem A, Armagan A (2006). Trends in hepatitis $B$ and hepatitis $C$ virus among blood donors over 16 years in Turkey. Eur. J. Epidemiol., 21: 299-305.

Knorr B, Maulb H, Schnitzler P (2008). Prevalence of hepatitis B virus infection among women at reproductive age at a German university hospital. J. Clin. Virol., 42: 422-424.

Kuzin SN, Ikoev VN, Shakhgil'dian IV, Gorbunov MA, Farber NA, Mikhălov MI (1990). Patterns in perinatal infection with the hepatitis $B$ virus in areas contrasted by the level of $\mathrm{HBsAg}$ and $\mathrm{HBeAg}$ carriage. Vopr. Virusol., 5: 304-306.

Lavanchy D (2004). Hepatitis B virus epidemiology, disease burden,treatment, and current and emerging prevention and control measures. J. Viral. Hepat., 11: 97-107.

Lee C, Gong Y, Brok J, Boxall EH, Gluud C (2006). Effect of hepatitis B immunisation in newborn infants of mothers positive for hepatitis $B$ surface antigen: Systematic review and metaanalysis. BMJ., 332: 328-323.

Mahoney FJ (1999). Update on diagnosis, management, and prevention of hepatitis B virus infection. Clin. Microbiol. Rev., 12: 351-366.

Margolis HS, Coleman PJ, Brown RE, Mast EE, Sheingold SH, Arevalo JA (1995). Control of hepatitis B virus transmission in the United States: an economic analysis of current recommendations. JAMA., 274: 1201-1208.

Mood BS, Keykhah F, Moghadam ES, Salehi M, Kohpayeh HR, Nayini RA (2004). Prevalence of Hepatitis B Surface Antigen in Pregnant Women in Zahedan, Iran. Hepatitis Monthly, 4: 161-163.

Papaevangelou G, Farmaki G, Kada H (1998). Hepatitis B maternalfetal transmission in Southern Europe. Intervirol., $41: 197-200$.

Papaevangelou V, Hadjichristodoulou C, Cassimos D, Theodoridou M (2006). Adherence to the screening program for HBV infection in pregnant women delivering in Greece. BMC. Infect. Dis., 6: 84.

Shapiro CN, Margolis HS (1992). Impact of hepatitis B virus infection on women and children. Infect. Dis. Clin. North Am., 6: 75 -96.

Stevens CE, Beasley RP, Tsui J, Lee WC (1975). Vertical transmission of hepatitis B antigen in Taiwan. N. Engl. J. Med., 292: 771.

Tajbakhsh E, Momtaz H, Momeni M, Hamedi S (2010). Molecular detection of hepatitis $B$ virus (HBV) among voluntary blood donor's HBsAg positive in shahrekord, Iran. Afr. J. Microbiol. Res., 4: 14191423.

UNICEF (2003) Bulletin.

Üner A, Kırımi E, Tuncer I, Ceylan A, Turkdogan MK, Abuhandan M (2001). Seroepidemiology of Hepatitis B Virus Infection in Children in The Eastern Anatolia. Eastern J. Med., 6: 40-42.

Zhu QR, Yu GJ, Yu H, Lu Q, Gu XH, Dong ZQ (2003). A randomized control trial on interruption of HBV transmission in uterus. Chin. Med. J., 116: 685-687. 